\title{
A Gestão da Política Monetária no Regime de Metas de Inflação e na Nova Matriz Econômica
}

\section{Monetary Policy Management under Inflation Targeting Regime and in the New Economic Matrix}

\author{
Thyago Américo Schio ${ }^{\mathrm{a}}$ \\ Vinicius Hiroshi Sato ${ }^{a}$ \\ Marcos Minoru Hasegawa
}

\begin{abstract}
Resumo: Este artigo investiga empiricamente a condução da política monetária por parte do Banco Central do Brasil no regime de metas de inflação, considerando os períodos de vigência do tripé macroeconômico (2000-2011) e da nova matriz econômica (2012-2014), identificando se existiram diferenças significativas na gestão da política monetária. Para tanto, identificam-se, através de vetores autorregressivos, as respostas da política monetária a choques em variáveis macroeconômicas derivadas de um modelo de Taylor modificado, contemplando o período do tripé macroeconômico e da nova matriz econômica. Como resultado, constata-se que prevaleceram diferenças significativas na gestão da política monetária entre os dois sistemas.
\end{abstract}

Palavras-chave: Política monetária. Taxas de juros. Regra de Taylor.

\begin{abstract}
This paper investigates the conduction of monetary policy by the Brazilian Central Bank during the Tripé Macro (TM) and the New Economic Matrix (NME). Specifically, we aim to identify if there were any significant differences in the management of monetary policy. In order to do so, through a Vector Auto Regressive, we detect the responses of monetary policy to shocks in macroeconomic variables, considering a modified Taylor model. The study consider the Inflation Targeting Regime period, observing the Tripé Macro (2000 to 2011) and the New Economic Matrix (2012 to 2014). As a result, we show that significant differences prevailed during the two systems.
\end{abstract}

Keywords: Monetary policy. Interest rates. Taylor rule.

JEL Classification: E52; E58.

a Universidade Federal do Paraná (UFPR), Programa de Pós-Graduação em Desenvolvimento Econômico (PPGDE), Departamento de Economia. Curitiba, Paraná, Brasil. 


\section{1 lntrodução}

A forma de condução da política monetária e os desafios enfrentados pelos policy makers são temas de amplo debate. Uma proposta destacada acerca da condução da política monetária foi elaborada por Taylor (1993). Nesse trabalho, Taylor propôs sua famosa regra - uma sugestão para a condução da política monetária.

A ideia básica da regra por ele proposta consiste em mensurar a taxa básica de juros de equilíbrio com base nas condições econômicas vigentes em um país. Especificamente, o autor argumenta que a política monetária deve ser determinada por regras transparentes e críveis e que essa é a forma mais eficaz para se atingir os melhores resultados conjuntos de desempenho econômico, resultados medidos pelas taxas de inflação e variação do crescimento econômico. Tal argumento foi utilizado para a adoção de regimes como o sistema de metas de inflação.

Em termos empíricos, diversos são os trabalhos elaborados com foco no Brasil que avaliam a resposta do Banco Central do Brasil (BCB) a variáveis macroeconômicas, como, por exemplo, inflação, produto e taxa de câmbio. Destacam-se Minella et al. (2002), Minella (2003), Policano e Bueno (2006), Modenesi (2008), Correia e Amaral (2008), Balbino, Colla e Teles (2011), Palma e Portugal (2011), Silva (2012), Costa Filho (2013), Barbosa, Camêlo e João (2016). De forma geral, os trabalhos sugerem mudanças nas preferências da autoridade monetária.

Este estudo, por sua vez, investiga empiricamente a condução da política monetária por parte do $\mathrm{BCB}$ no RMI (RMI), considerando os períodos do tripé macroeconômico (TM) e da nova matriz econômica (NME), identificando se existiram diferenças significativas na gestão da política monetária. ${ }^{1}$ Posto de outra forma, a seguinte questão norteia a pesquisa: a condução da política monetária sofreu mudanças significativas no período entre 2000 e 2011 (TM) e 2012 e 2014 (NME)? Trata-se de uma pesquisa inédita na área e de alta relevância. Em geral, especula-se que, na NME, prevaleceu uma dinâmica essencialmente distinta do TM quanto à gestão da política monetária, notadamente em vista da forma como o $\mathrm{BCB}$ reagiu a choques nas variáveis econômicas.

Metodologicamente, identificam-se através de vetores autorregressivos (VAR) as respostas da política monetária a choques em variáveis macroeconômicas em um modelo de Taylor modificado, contemplando o período do TM e da NME. Dessa forma, o presente artigo, além de apresentar evidências da veracidade dessa especulação, contribui com a literatura empírica ao esclarecer a forma como as autoridades monetárias reagiram a choques nas variáveis econômicas.

O presente artigo está dividido em mais cinco seções, além desta introdução: a segunda apresenta a revisão de literatura; a terceira explana os fundamentos

1 A conceituação do RMI, do TM e da NME é apresentada na revisão de literatura. 
teóricos; a quarta aborda a metodologia; a quinta explica os resultados; e, por fim, a sexta traça as considerações finais.

\section{Revisão de Literatura}

A revisão de literatura aborda dois pontos. Em primeiro lugar, é feita uma breve exposição acerca do RMI, vigente durante o período do TM que norteou a política econômica de 1999 a 2011, bem como da condução da política monetária durante a NME, a qual foi a norteadora da política econômica de 2012 a 2014. Em segundo lugar, é apresentada uma resenha acerca dos trabalhos empíricos que abordaram a condução da política monetária brasileira, especialmente a partir da adoção do RMI no país.

\subsection{As Diretrizes da Política Econômica Brasileira de 1999 a 2014: o Tripé Macroeco- nômico e a Nova Matriz Macroeconômica}

Objetivamente, o RMI consiste em um regime monetário no qual o $\mathrm{BCB}$ se comprometeu a atuar de forma a garantir que a inflação efetiva esteja em linha com uma meta previamente estabelecida. Nesse sistema, a ação do BCB foi norteada pelo controle da taxa de juros de curto prazo, sem meta adicional, como, por exemplo, crescimento econômico ou taxa de câmbio. Ainda assim, essas e outras variáveis podem ser levadas em consideração em um cenário prospectivo para a inflação, permitindo, assim, certa flexibilidade ao regime quanto à sua forma de atuação.

Nesse sentido, Mishkin (2000) explicita os cinco elementos para operacionalização do RMI: a) anúncio público da meta numérica para a inflação; b) compromisso institucional com a estabilidade de preços como principal objetivo da política monetária, de modo que outras metas estejam subordinadas a esta; c) explicitação da forma pelas quais diversas variáveis, e não apenas os agregados monetários ou a taxa de câmbio, afetam as decisões de uso dos instrumentos de política; d) crescente transparência acerca da estratégia de política monetária, por meio da comunicação com o público e com os mercados sobre os planos, objetivos e decisões da autoridade monetária; e) atribuição da responsabilidade ao $\mathrm{BCB}$ para cumprimento da meta de inflação estipulada.

No RMI, e atrelado aos itens $c$ e $d$, a meta de inflação possibilita à autoridade monetária o uso de todas as informações disponíveis, e não apenas uma variável, visando controlar a política monetária. Além disso, há duas importantes características do RMI, conforme exposto por Bernanke e Mishkin (1997, p. 11): 
Primeiro, a nível técnico, meta de inflação não se qualifica como uma regra política que não provê instruções operacionais simples e mecânicas para o Banco Central [...]. Segundo, e mais importante [o regime de] meta de inflação, como é atualmente praticado, contém um considerável grau do que muitos economistas definem como política discricionária [...].

Operacionalmente, no RMI, o BCB, visando cumprir sua finalidade operacional, anuncia uma meta numérica para a taxa de inflação - podendo ser um ponto ou uma banda -, bem como um horizonte de tempo para a meta inflacionária ser atingida. Como parâmetro para a meta de inflação, costumeiramente os bancos centrais definem os índices de preços a serem referenciados. Tradicionalmente, duas opções são utilizadas. No primeiro caso, têm-se índices cheios, como é o caso do índice de preços ao consumidor no Brasil. ${ }^{2}$ Além disso, há a opção do núcleo da inflação, que exclui do índice de preços referenciado itens que oscilam significativamente e que causam perturbações transitórias ou autocorrigíveis, possuindo pouca relação com movimentos permanentes nos preços.

Biondi e Toneto Júnior (2008) sustentam que o TM foi a diretriz da política macroeconômica brasileira, introduzida em 1999, que buscou basear a política macroeconômica do país no tripé considerado à época como o mais consistente por acadêmicos, policy makers e organismos internacionais. Em específico, baseando-se em três pilares: a) câmbio flutuante, a peça do tripé destinada a garantir o ajustamento do balanço de pagamentos; b) equilíbrio fiscal, objetivando o controle da demanda agregada e flutuações expressivas no câmbio; c) metas de inflação, utilizando-a como a âncora nominal do sistema, importante para a manutenção da inflação baixa, e a possiblidade de instabilidade econômica em um contexto de ampla variabilidade de preços. No mesmo diapasão, mas apresentando o TM de outra forma, Oreiro (2015) afirma que o TM foi a base da política macroeconômica brasileira entre 1999 e 2011 , tendo sido desenhado buscando três objetivos: a) estabilização da dívida pública em relação ao PIB; b) garantia da estabilidade da taxa de inflação; c) flexibilidade para a política monetária atender objetivos domésticos, ao invés de ser conduzida visando ajuste do balanço de pagamentos. De acordo com o autor, houve sucesso por parte do TM em cumprir tais objetivos, observando o período entre 1999 a 2011.

Alternativamente ao TM, norteador da política macroeconômica durante de 1999 a 2011, adotou-se, nos anos de 2012 a 2014, a NME, a nova norteadora da política macroeconômica (OREIRO, 2015; VELOSO; BONELLI, 2016; BARBOSA FILHO, 2017). Como salientou o ministro da Fazenda à época, Mantega (2010), em artigo divulgado à imprensa no fim de 2012, a NME consistia em uma diretriz

2 Outras boas análises acerca do RMI e o caso brasileiro são apresentadas por Carrara e Correa (2012) e Braga e Pereira (2014). 
para a política macroeconômica, induzindo a mudança de preços relativos, com juros mais baixos e taxa de câmbio mais depreciada, combinação que objetivava impulsionar o crescimento industrial e da renda nacional e simultaneamente reduzir os encargos dos juros incidentes sobre a dívida pública, de forma a possibilitar redução da carga tributária e do esforço fiscal.

De acordo com Veloso e Bonelli (2016), a NME correspondeu à alternativa ao TM, tendo sido adotada a partir do ano de 2012, caracterizando-se pelo aumento da discricionariedade da política econômica. Nesse sentido, o seguinte conjunto de medidas foi adotado nesse período: a) alteração do regime de câmbio flutuante para fortemente administrado; b) redução da transparência e do esforço da política fiscal; c) reduções artificiais da taxa básica de juros e maior leniência com a inflação; d) controle de preços como mecanismo de controle inflacionário; e) redução do papel das agências reguladoras; f) expansão do crédito subsidiado, sobretudo por meio do Banco Nacional de Desenvolvimento Econômico e Social (BNDES), intentando-se o aumento do investimento; g) ampliação de políticas discricionárias, como as desonerações tributárias seletivas.

A despeito das significativas mudanças introduzidas pela NME a partir do ano de 2012, é importante observar que não houve um rompimento formal e explícito, em termos de regime monetário, com o RMI. ${ }^{3}$ Especificamente, Veloso e Bonelli (2016) destacam que a principal característica da política monetária nesse período foi o relaxamento em relação à perseguição do centro da meta inflacionária, tolerando-se a convivência com o teto da meta, além da introdução do controle artificial de preços para o controle inflacionário. Ainda assim, durante todo o período de vigência da NME, a meta de inflação foi definida como 4,5\% ao ano, por meio do Índice Nacional de Preços ao Consumidor Amplo (IPCA). Por tal razão, não houve o abandono formal do RMI durante os anos da NME.

\subsection{Evidências Empíricas acerca da Condução da Política Monetária}

Minella et al. (2002) desenvolveram um dos primeiros estudos acerca da condução da política monetária no Brasil por parte do BCB durante o RMI. No trabalho, os autores estimaram funções de reação do BCB através de modelos VAR, contemplando o período entre junho de 1999 e junho de 2002. Como resultados, verificaram que o $\mathrm{BCB}$ reagiu fortemente às expectativas de inflação e às pressões inflacionárias, mostrando o viés forward looking da política monetária. Evidenciaram reduções no grau de persistência inflacionária. Também demonstraram que o $\mathrm{BCB}$ ajustou a taxa Selic de forma gradual, evidenciando o forte componente inercial da Selic. Por fim, mostraram o elevado pass-through da taxa de câmbio para os preços, notadamente dos preços administrados. Concluindo, apontaram que o

3 Além de Veloso e Bonelli (2016), Oreiro (2015) e Barbosa Filho (2017) salientam esse ponto. 
BCB conduziu no período a política monetária com certa discricionariedade, buscando identificar as fontes de inflação e direcionando adequadamente a política monetária face aos choques constatados.

Minella (2003) estimou três modelos VAR entre os anos de 1975 e 2000, examinando a política monetária e relações macroeconômicas envolvendo produto, inflação, juros e moeda no Brasil. Dividiu a análise em três períodos da economia brasileira: inflação moderada e crescente (1975-1985), elevada inflação (19851994) e baixa inflação (1994-2000). Verificou que, no último período analisado, a política monetária não respondeu ativamente aos choques na taxa de inflação e do produto, mas sim a crises financeiras. Ainda, identificou que o grau de persistência inflacionária foi significativamente menor no último período analisado. Concluindo, sustentou que no período recente - e distintamente dos dois primeiros períodos - a política monetária ganhou poder para afetar os preços, o que pode estar relacionado à redução substancial do grau de persistência da inflação.

Policano e Bueno (2006) estimaram funções de reação do BCB 4 antes e após a implementação do sistema de metas para inflação. Especificamente, dividiram a análise em dois períodos: o primeiro de 1995 a 1999 e o segundo de 1999 a 2006. Metodologicamente, utilizaram parâmetros variantes no tempo (PVT), coeficientes variando de período a período, com dados mensais. Mostraram que o comportamento da política monetária desde a implementação do plano real seguiu diferentes padrões. Nesse sentido, como resultados empíricos, obtiveram que, para o primeiro período (com regime de câmbio fixo), prevaleceu uma reação da taxa de juros em relação ao produto e às variações no câmbio. Por sua vez, no segundo período a taxa de juros reagiu às expectativas de inflação, sendo mais evidente a partir de 2003. Ainda, frisaram que a condução da política monetária durante o segundo período deixou de ser guiada diretamente pelas variáveis relevantes dos anos anteriores, passando a se concentrar nos desvios da meta da inflação. Não obstante, frisaram que as outras variáveis antes mais relevantes, como o hiato do produto, a taxa de câmbio e a taxa de inflação, não deixaram de ser importantes, porém passaram a ter influências indiretas, visto que todas afetam as expectativas de inflação.

Modenesi (2008) avaliou a condução da política monetária no Brasil após a adoção do RMI em 1999. Para tanto, estimou uma função de reação do BCB para avaliar a condução da política monetária no Brasil após a adoção do RMI. Analisou o período entre 1999 e 2007. Como resultados, apontou que ocorria elevado grau de inércia na taxa básica de juros, prevalecendo um excessivo grau de suavização na determinação da taxa básica de juros, bem como um elevado nível na taxa de equilíbrio. Argumentou, ainda, que a rigidez monetária possui elementos distintos do meramente macroeconômicos, existindo uma coalizão de interesses pela manutenção dos juros em níveis elevados. De acordo com Modenesi (2008, p. 10):

$4 \quad$ Outra nomenclatura empregada para se referir à regra de Taylor ou suas variantes. 
Em síntese, o BCB dá pouca atenção ao estado da economia (medido pelo desvio da inflação em relação a sua meta e pelo hiato do produto) imprimindo demasiado gradualismo - mais do que o praticado, por exemplo, pelo Federal Reserve (FED) - na definição dos juros básicos. $\mathrm{O}$ gradualismo do BCB, aliado a um nível muito elevado da taxa de equilíbrio, significa que a SELIC fatalmente tende a flutuar no entorno de um patamar demasiadamente alto.

Correia e Amaral (2008) analisaram empiricamente a função de reação do BCB através de um VAR, contemplando o período entre 2001 e 2007. Decompuseram os impactos dos preços administrados e livres sobre a taxa Selic e, distintamente da maioria dos trabalhos elaborados, utilizaram a regra de Taylor em função do IPCA. No modelo, usaram como variáveis explicativas para a Selic a taxa de câmbio, a taxa de utilização da capacidade produtiva, a expectativa de inflação para os próximos 12 meses, os preços livres e administrados e a relação dívida/ PIB. Como resultados, obtiveram que a resposta do BCB, via regra de Taylor, foi explicada diretamente pelas variáveis nível de utilização da capacidade produtiva e expectativas para a inflação dos próximos 12 meses, medida pelo IPCA. Identificaram um mecanismo de causalidade indireta em que a taxa de câmbio causou fortemente as expectativas de inflação e, portanto, mesmo que indiretamente, influenciou na determinação da taxa Selic.

Balbino, Colla e Teles (2011) analisaram a evolução da política monetária no período de 1999 a 2009, verificando se prevaleceram diferenças na condução da política monetária entre as gestões de Armínio Fraga e Henrique Meirelles. Para tanto, utilizaram um modelo de equilíbrio geral novo-keynesiano baseado em expectativas racionais, derivando-se uma regra de Taylor para encontrar a condição suficiente para a convergência da inflação. Especificamente, estimaram um modelo VAR com PVT. Como resultados, obtiveram que não houve diferenças significativas na condução de política monetária durante as gestões Armínio Fraga e Henrique Meirelles. Além disso, a partir de 2003, a taxa de juros permaneceu acima da necessária para a convergência da inflação. Por fim, identificaram que a gestão Armínio Fraga agiu de acordo com a regra de estabilização na crise de 2002, porém a inflação permaneceu acima da meta em virtude da magnitude dos choques exógenos. Ainda, frisaram que existe um grande espaço para discricionariedade, principalmente na condução das políticas, a qual foi observada no período analisado.

Por sua vez, Palma e Portugal (2011) analisaram as preferências do BCB durante o RMI, usando um modelo novo-keynesiano padrão com expectativas forward-looking. A análise considerou o período entre 2000 e 2010. Separaram as políticas em dois casos possíveis, regras e discrição, avaliando com qual desses casos os dados foram mais consistentes. Usando observações trimestrais, evidenciaram que, para o período considerado, os dados favoreceram a política discricionária. Especificamente, as estimativas da função perda revelaram que a auto- 
ridade monetária deu grande peso para a estabilização da inflação, seguida pela suavização da taxa de juros e pela estabilização do hiato do produto. Concluindo, sustentaram que o BCB adotou um regime flexível de metas de inflação compatível com uma política monetária discricionária durante o período.

Já Silva (2012) procurou evidências de que o BCB seguia uma regra de Taylor aumentada, considerando preços de ativos financeiros. A análise foi conduzida para o período entre 2000 a 2012. Para o fim proposto, desenvolveu um índice que incorpora os preços de ativos dos mercados acionário, imobiliário e cambial, cujos pesos variaram ao longo do tempo. Para estudar o caso brasileiro, estimou uma função de reação não linear através da metodologia de Markov switching regime e analisou os resultados encontrados e seus desdobramentos. Em síntese, verificou que o BCB não seguiu uma regra de Taylor aumentada na condução da política monetária e encontrou evidências de não linearidade da regra de Taylor do BCB. Como justificativa, afirmou que o resultado é compatível com a ideia de que a função de reação do BCB ao longo do período de existência do RMI foi orientada majoritariamente pela meta de promoção da estabilidade monetária, tendo utilizado outros mecanismos para a promoção da estabilidade financeira do sistema. Também identificou que houve mudança na função de reação a partir de 2009 , quando o BCB passou a dar peso significativamente maior ao hiato do produto relativamente ao desvio da inflação em relação à meta. Por fim, defendeu que a mudança na função de reação do BCB pode ter sido resultado do reconhecimento do recuo da taxa de juros real de equilíbrio (ou neutra) da economia brasileira.

Costa Filho (2013) estimou uma regra de Taylor aumentada para a economia brasileira no período entre 2003 e 2010, o qual teve Henrique Meirelles presidindo o BCB. Em resumo, concluiu que a política monetária foi conduzida de forma estrita, reagindo fortemente aos desvios das expectativas da inflação em relação à meta, bem como aos da própria inflação, além de ter reagido ao hiato do produto, ainda que dando menor ênfase a essa variável. Ainda, ressaltou o elevado coeficiente de suavização das taxas de juros, demonstrando o gradualismo durante o período em que Henrique Meirelles presidiu o BCB. Nessa linha, ressaltou a forte resposta da autoridade monetária aos desvios da inflação, apontando, assim, que a política monetária foi estabilizadora no período, posto que ocorreram aumentos reais dos juros mais do que proporcionais ao aumento da taxa de inflação.

Por fim, Barbosa, Camêlo e João (2016) estimaram uma regra de Taylor aumentada para a economia brasileira no período entre 2003 a 2015 . O trabalho teve por objetivo estimar a taxa de juros natural da economia brasileira, supondo que se trata de uma economia aberta pequena. De forma complementar, o trabalho também teve como objetivo testar a hipótese de que a função de reação do BCB mudou os seus parâmetros no primeiro mandato da presidente Dilma. Como resultados, identificou-se que as estimativas para a taxa de juros natural revelaram 
uma forte queda até o começo desta década, com uma breve reversão a partir de meados de 2012. Os resultados também indicaram que, durante o governo Dilma, o $\mathrm{BCB}$ passou a dar um menor peso à inflação e maior peso ao hiato de produto, embora não tenha alterado suas reações à variação do câmbio. A evidência empírica não rejeitou a hipótese de que o BCB mudou sua função de reação no primeiro mandato da presidente Dilma. Nesse sentido, Barbosa, Camêlo e João (2016, p. 18) sustentam que:

A evidência empírica encontrada por este trabalho sugere que, durante o primeiro governo de Dilma Roussef, o Banco Central teve uma postura significativamente mais leniente do que em todo os outros anos analisados, o que pode ser entendido como uma das razões de a inflação ter ficado consistentemente acima da meta desde 2011.

Finalizando a resenha elaborada dos trabalhos citados, as conclusões obtidas acerca dos trabalhos empíricos conduzidos que tratam da condução da política monetária no Brasil são, em resumo, as seguintes: a) no período de vigência do RMI, acerca do período entre os anos de 1999 a 2011 (TM), predominou uma postura do $\mathrm{BCB}$ a qual priorizou a estabilidade inflacionária, atentando-se especialmente para as expectativas de inflação e os desvios da inflação em relação à meta, dando-se menor atenção ao estado da economia. Ainda, a discrição da autoridade monetária foi observada, bem como o componente gradualista da política monetária, cujo principal característica residiu na suavização das mudanças na taxa de juros; b) a política monetária foi impactada pela crise econômica iniciada em 2009, tendo se tornado menos inflexível em relação aos desvios da inflação e dado maior atenção ao hiato do produto; c) no período entre os anos de $2011 \mathrm{e}$ 2012 (NME), houve aprofundamento da mudança na condução da política monetária, ampliando-se a leniência com os desvios da meta de inflação e com taxas de inflação maiores, além de se ter rompido com o gradualismo na suavização das mudanças da política monetária que caracterizaram o período anterior.

\section{Fundamentos Teóricos}

De acordo com Modenesi (2008), no Brasil a condução da política monetária está inserida no contexto do novo consenso macroeconômico, cujo principal objetivo da política monetária é o controle inflacionário. Nessa concepção, a inflação é tida como um fenômeno de natureza monetária. Dessa forma, a taxa de juros atua como principal instrumento do BCB para estabilizar a inflação no longo prazo, sendo reconhecido o seu impacto sobre a demanda agregada apenas no curto prazo.

No contexto do novo consenso macroeconômico, emergiu a regra de Taylor (TAYLOR, 1993), que consiste no pilar da política monetária. A ideia básica des- 
sa regra reside em determinar a taxa básica de juros de equilíbrio com base nas condições econômicas vigentes em um país. $\mathrm{O}$ autor argumenta que a política monetária deve ser determinada por regras transparentes e críveis e que essa é a forma mais eficaz para se atingir os melhores resultados conjuntos de desempenho econômico, resultados medidos pelas taxas de inflação e variação do crescimento econômico. Tal argumento foi utilizado para a adoção de regimes como o sistema de metas de inflação, atualmente em vigor no Brasil.

Especificamente, Taylor (1993) sugeriu uma regra para a taxa de juros de curto prazo. Nela, o BCB poderia defini-la levando em consideração quatro variáveis: inflação presente, taxa de juros de equilíbrio, desvio da inflação e hiato do produto. $\mathrm{O}$ autor sustentou, ainda, que essa política monetária poderia manter a inflação baixa e estável.

Dito isso, a política monetária identifica a taxa de juros, normalmente dada pela função de reação do BCB, derivada da regra de Taylor:

$$
i_{t}=r^{*}+\pi_{t}+0,5\left(\bar{Y}_{t}\right)+0,5\left(\bar{\pi}_{t}\right)
$$

Na qual $i_{t}$ é a taxa de juros nominal, $r^{*}$ é a taxa natural de juros, $\pi_{t}$ é a taxa de inflação, $\bar{Y}_{t}$ representa o hiato do produto e $\bar{\pi}_{t}$ consiste no desvio da inflação em relação à sua meta.

Segundo Mendonça (2003), os dois primeiros fatores servem de referência para o caso em que a economia está operando ao nível potencial e revelam a hipótese implícita do uso de uma taxa real de juros constante. Já o terceiro e o quarto fator da regra de Taylor representam os dois objetivos da política monetária, nos quais os parâmetros de ajuste referem-se ao trade-off de curto prazo entre a inflação e o produto.

Ressalta-se que essa regra resultou de um estudo empírico acerca da condução da política monetária conduzido pelo Federal Reserve Bank (FED) durante os anos de 1987 a 1992. Embora empírico, não se tratou de um modelo econométrico, sendo que o autor assumiu que os pesos utilizados pelo FED em relação aos desvios da inflação e o PIB seriam de 0,5.

Nesse modelo, se, por exemplo, a inflação fosse um ponto percentual acima da meta, o FED elevaria em $0,5 \%$ as taxas de juros. O mesmo raciocínio se aplica ao hiato do produto. Em síntese, Taylor apresentou uma descrição da política de taxa de juros cujo papel da regra monetária é mostrar o caminho ao longo do qual a economia é guiada pela política monetária a seu caminho de equilíbrio do produto com inflação controlada.

Salienta-se que, na interpretação convencional da regra de Taylor, choques de diversas naturezas, como choques inflacionários, de demanda, de oferta, temporários ou permanentes, provocam a mesma reação na autoridade monetária. 


\section{Metodologia}

Na literatura, modificações da especificação original de Taylor são frequentes, como, por exemplo, uso de expectativas em relação às variáveis meta (como inflação), inclusão da taxa de juros defasada no conjunto das variáveis explicativas, entre outros. Nesse diapasão, destacam-se os trabalhos de Clarida, Galí e Gertler (1998), Gali, Lopez-Salido e Valles (2007), Choi e Wen (2010), Minella et al. (2003), Bueno (2005), Policano e Bueno (2006), Correia e Amaral (2008), Balbino, Colla e Teles (2011) e Campos (2015).

No trabalho proposto, estima-se uma função de reação do BCB modificada (trata-se de uma regra de Taylor modificada), usando-se para tanto um VAR, mapeando-se as funções de respostas da taxa de juros frente a choques nas seguintes variáveis: desvio da inflação frente à meta, expectativas de inflação, hiato do produto, resultado nominal, participação das letras financeiras do tesouro em relação aos títulos do Tesouro Nacional e taxa de câmbio.

O VAR foi estimado por Mínimos Quadrados Ordinários (MQO) e em nível, ${ }^{5}$ ainda que contendo variáveis não estacionárias devido às análises objeto deste estudo. Sims, Stock e Watson (1990) justificam que o objeto da análise através do VAR é determinar as relações existentes entre as variáveis, e não os parâmetros estimados. Nesse sentido, o apropriado é se estimar o VAR em nível. Ademais, um VAR com variáveis diferenciadas (no contexto proposto) demonstra como mudanças na variação das variáveis do modelo provocam mudanças na variação da taxa Selic. Não é este o objetivo do estudo.

Hamilton (1994) explicita que, na ausência de autocorrelação, os valores dos parâmetros estimados de um VAR em nível são idênticos aos valores dos parâmetros de um VAR estimado em diferenças. No VAR estimado em nível, cada coeficiente individual autorregressivo converge a uma taxa $\sqrt{T}$ para uma variável gaussiana. Desse modo, os testes individuais de hipóteses $t$ acerca dos coeficientes estimados são assintoticamente válidos. ${ }^{7}$

Para Hamilton (1994), há duas características importantes no modelo VAR em nível, em que cada equação é estimada por MQO: ${ }^{8}$ a) os parâmetros que descrevem o sistema dinâmico são consistentes e assintoticamente eficientes; b) ainda que o verdadeiro modelo seja um VAR em diferenças, certas funções dos parâ-

5 Sims, Stock e Watson (1990) apresentam todo o detalhamento das características do VAR em nível.

6 T representa o tamanho da amostra da série temporal. Em outras palavras, a velocidade de convergência é proporcional ao tamanho amostral.

7 Em modelos multivariados com variáveis não estacionárias, inferências sobre hipóteses conjuntas só podem ser feitas se, no modelo, os coeficientes a serem testados passem a multiplicar variáveis estacionárias (BUENO, 2011).

8 Nesse caso, requer-se que os erros não sejam serialmente correlacionados. 
metros e os testes de hipóteses baseados em um VAR em nível possuem a mesma distribuição assintótica do VAR estimado em diferenças.

No estudo proposto, estimam-se as funções de reação para dois períodos: 2000 a 2011 (TM) e 2012 a 2014 (NME). Essa proposição traz ricas informações acerca da condução e dinâmica da política monetária face a dois regimes citados. Ademais, permite responder a indagação apresentada na introdução. Isso posto, propõe-se a seguinte a regra de Taylor modificada:

$$
i_{t}=\alpha+\beta_{1}\left(\bar{Y}_{t}\right)+\beta_{2}\left(\bar{\pi}_{t}^{e}\right)+\beta_{3} \varphi_{t}+\beta_{4} R N_{t}+\beta_{5} \theta_{t}+\beta_{6} L F T_{t}
$$

em que $i_{t}$ é a taxa de juros nominal (Selic), $\bar{Y}_{t}$ representa o hiato do produto, medido pela diferença entre a série PIB mensal e ele após uso do filtro HodrickPrescott ${ }^{9}, \bar{\pi}_{t}^{e}$ consiste na expectativa da inflação para os próximos 12 meses, $\varphi_{t}$ denota o desvio da inflação acumulada em 12 meses face à meta oficial do $\mathrm{BCB}, \mathrm{RN}$ é a necessidade de financiamento do setor público, resultado nominal do governo federal como porcentagem do PIB, $\theta_{t}$ é a taxa de câmbio nominal e LFT representa a parcela das Letras Financeiras do Tesouro em relação ao total da dívida mobiliária emitida pelo Tesouro Nacional.

Com efeito, nesse modelo se assume que a taxa de juros reage não somente às variações nas expectativas da inflação e ao hiato do produto, mas também às variações do resultado nominal e da taxa de câmbio, ao prêmio de risco da economia brasileira e à parcela das Letras Financeiras do Tesouro em relação ao total da dívida mobiliária emitida pelo Tesouro Nacional.

Esse modelo apresenta a seguinte formulação em forma de VAR:

$$
X_{t}=B_{0}+\sum_{i=1}^{p} A_{i} X_{t-i}+B \varepsilon_{t}
$$

na qual as seis variáveis endógenas que constituem o vetor $6 \times T$ são apresentados em (2). As matrizes $A_{i}$ são de sexta ordem e $B$ é uma matriz diagonal de sexta ordem de desvios padrões, enquanto o termo de erro $\varepsilon_{t}$ é um vetor 6 x $T$ de perturbações estocásticas não correlacionadas entre si contemporaneamente ou temporalmente, ou seja, $\varepsilon_{t} \sim \operatorname{idd}\left(0, \sigma^{2} I_{n}\right)$.

As variáveis de análise foram selecionadas considerando-se o debate teórico (seções 2 e 3 deste artigo), ${ }^{10}$ o quadro norteador do RMI no Brasil durante o período discutido (seção 2.1), bem como a condução da política monetária, atentando-se às

9 Trata-se de uma ferramenta amplamente utilizada em macroeconomia para remover o componente cíclico de séries temporais. Para mais detalhes, ver Kydland e Prescott (1982).

10 Um aprofundamento do debate teórico acerca do problema das taxas de juros no Brasil e a política monetária brasileira é apresentado por Modenesi e Modenesi (2012). 
variáveis-chave apresentadas na literatura resenhada (seção 2.2). Frisa-se que as variáveis empregadas no modelo são cruciais diante dos pontos expostos, sendo todas adequadas e necessárias para responder o problema de pesquisa que norteia o estudo.

No Quadro 1, são apresentadas as variáveis analisadas na pesquisa, suas justificativas, os períodos a serem analisados e as fontes dos dados.

Quadro 1 - Variáveis analisadas na pesquisa a partir de janeiro de 2000 (01/2000) até dezembro de 2014 (12/2014) com periodicidade mensal

\begin{tabular}{|c|c|c|}
\hline Série & Justificativa & Fonte \\
\hline $\begin{array}{l}\text { Taxa de juros interna (Selic): } \\
\text { indicador da taxa interna de } \\
\text { juros anualizada, acumulada do } \\
\text { mês. }\end{array}$ & $\begin{array}{l}\text { Variável-chave e essencial do modelo. Variável objetiva } \\
\text { na formulação original de Taylor. No RMI, é definida } \\
\text { pelo Copom. }\end{array}$ & $\mathrm{BCB}$ \\
\hline $\begin{array}{l}\text { Hiato do produto }(\bar{Y}) \text { : indicador } \\
\text { do hiato do produto, obtido } \\
\text { através da diferença entre } \\
\text { estimativa mensal do PIB }(\mathrm{BCB}) \\
\text { e ele mesmo após uso do filtro } \\
\text { Hodrick-Prescott. }\end{array}$ & $\begin{array}{l}\text { Contida na formulação original de Taylor. Variável- } \\
\text { chave no modelo teórico e no debate sobre a condução } \\
\text { da política monetária brasileira e de ampla presença } \\
\text { nos trabalhos abordados na revisão da literatura. Versa } \\
\text { sobre o lado real da atividade econômica. }\end{array}$ & $\begin{array}{l}\text { Estimado } \\
\text { a partir } \\
\text { de dados } \\
\text { do BCB. }\end{array}$ \\
\hline $\begin{array}{l}\text { Expectativa da inflação para os } \\
\text { próximos } 12 \text { meses }(\bar{\pi}) \text { : indicador } \\
\text { da expectativa de mercado } \\
\text { para a inflação nos próximos } 12 \\
\text { meses. }\end{array}$ & $\begin{array}{l}\text { Variável-chave no modelo teórico, crucial no RMI, } \\
\text { no debate sobre a condução da política monetária } \\
\text { brasileira e de ampla presença nos trabalhos abordados } \\
\text { na revisão da literatura. Versa sobre as expectativas dos } \\
\text { agentes e de ancoragem dessas expectativas. } \\
\end{array}$ & $\mathrm{BCB}$ \\
\hline $\begin{array}{l}\text { Desvio da inflação acumulada } \\
\text { em } 12 \text { meses - meta oficial do } \\
\text { BCB }(\varphi) \text { : indicador obtido a } \\
\text { partir do IPCA/IBGE. }\end{array}$ & $\begin{array}{l}\text { Contida na formulação original de Taylor. Variável- } \\
\text { chave no modelo teórico, crucial no RMI, no debate } \\
\text { sobre a condução da política monetária brasileira e de } \\
\text { ampla presença nos trabalhos abordados na revisão da } \\
\text { literatura. Versa sobre os desvios da inflação em relação } \\
\text { à meta e, assim, indiretamente no comprometimento } \\
\text { da autoridade monetária e com a ancoragem de } \\
\text { expectativas. }\end{array}$ & $\mathrm{BCB}$ \\
\hline $\begin{array}{l}\text { Resultado nominal do setor } \\
\text { público }(\mathrm{RN}) \% \text { PIB: aponta o } \\
\text { resultado nominal do governo } \\
\text { federal em relação à renda } \\
\text { nacional. Indicador da situação } \\
\text { fiscal no Brasil. }\end{array}$ & $\begin{array}{l}\text { Variável-chave no debate teórico e sobre a condução } \\
\text { da política monetária brasileira e de ampla presença } \\
\text { nos trabalhos abordados na revisão da literatura. Trata } \\
\text { da questão fiscal atrelada ao montante de recursos que } \\
\text { o setor público demanda do setor privado para realizar } \\
\text { suas despesas orçamentárias. }\end{array}$ & $\mathrm{BCB}$ \\
\hline $\begin{array}{l}\text { Taxa de câmbio (CAMB) - R } \$ \text { / } \\
\text { US\$ - comercial - compra - } \\
\text { média - R } \$(\theta) \text { : indicador do } \\
\text { preço do dólar em reais. }\end{array}$ & $\begin{array}{l}\text { Variável-chave no debate teórico e sobre a condução } \\
\text { da política monetária brasileira e de ampla presença nos } \\
\text { trabalhos abordados na revisão da literatura. Além disso, } \\
\text { além de indicar os preços relativos das moedas, introduz } \\
\text { indiretamente no modelo influências internacionais, } \\
\text { como ciclos de liquidez, influxos de capitais, taxa externa } \\
\text { de juros. }\end{array}$ & $\mathrm{BCB}$ \\
\hline
\end{tabular}

Continua... 


\begin{tabular}{|l|l|l|}
\hline Série & Justificativa & Fonte \\
\hline Letras Financeiras do Tesouro & Variável-chave no debate teórico e sobre a condução \\
(LFT): letras financeiras do & da política monetária brasileira e de ampla presença nos & Estimado \\
Tesouro em relação ao total da & trabalhos abordados na revisão da literatura. Além disso, \\
dívida mobiliária emitida pelo & de dados \\
Tersa sobre a indexação da economia, especialmente & do BCB. \\
Tesouro Nacional. & $\begin{array}{l}\text { Letras Financeiras do Tesouro em relaçãa ao total da } \\
\text { dívida permite a redução da Selic. }{ }^{11}\end{array}$ & \\
\hline
\end{tabular}

Fonte: Elaboração própria.

Como anteriormente exposto, a segmentação do período de análise ocorre de janeiro de 2000 a dezembro de 2011, qualificado como o período do TM, e de janeiro de 2012 a dezembro de 2014, considerado como o período da NME. Tal segmentação possibilita se confrontar os resultados das reações promovidas pela autoridade monetária frente a choques nas variáveis de análise.

\section{Resultados}

Os resultados são apresentados em cinco tópicos, tratando previamente da parte estatística, e nos dois tópicos finais, os resultados e suas implicações.

\section{1 ldentificação de Estacionariedade e Quebra Estrutural nas Séries Econômicas}

Para se analisar a hipótese de mudança estrutural entre os períodos de vigência do TM e da NME, foi realizado o teste de Chow, conforme descrito por Hamilton (1994). O ponto de quebra avaliado foi estabelecido entre dezembro de 2010 e janeiro de 2011, obtendo como resultado uma estatística $F$ de 4,552 e um p-valor de 0,0001134. Com efeito, rejeita-se a hipótese nula de estabilidade dos coeficientes entre as duas etapas da política econômica. Desse modo, sustenta-se que ocorreu uma alteração significativa da condução macroeconômica nesse intervalo temporal, implicando uma mudança estrutural no relacionamento entre as variáveis do modelo.

Com o intuito de se identificar a ordem de integração, foram realizados dois testes de raiz unitária nas variáveis utilizadas no modelo. Para tanto, foram realizados os testes KPSS e NG-Perron.

No Quadro 2, são apresentados os resultados obtidos para os dois períodos analisados. Constata-se que, em determinados modelos, certas variáveis apresentaram rejeição à hipótese de raiz unitária, sugerindo, assim, que a variável

11 As Letras Financeiras do Tesouro são títulos pós-fixados que evoluem de acordo com a Selic. Como constituem uma parcela relevante do estoque da dívida pública, a manutenção da Selic em níveis elevados resulta em um custo financeiro igualmente alto. Eis a razão para se buscar reduzir a parcela desse título em relação ao total da dívida pública. 
em questão é estacionária em nível. Os Quadros 2 e 3 apresentam o detalhamento das estatísticas.

Quadro 2 - Testes de raiz unitária para as variáveis do modelo em nível: período de janeiro de 2000 a dezembro de 2011 (TM)

\begin{tabular}{|l|c|c|c|c|c|}
\hline Variável & \multicolumn{2}{|c|}{ Teste KPSS } & \multicolumn{2}{c|}{ Teste NG Perron } & Conclusão $^{\mathbf{1 2}}$ \\
\hline & Constante & $\begin{array}{c}\text { Constante e } \\
\text { tendência }\end{array}$ & Constante & $\begin{array}{c}\text { Constante e } \\
\text { tendência }\end{array}$ & \\
\hline $\bar{Y}$ & 0,052 & 0,048 & 1,023 & 0,237 & Estacionária \\
\hline $\bar{\pi}$ & $0,736^{* *}$ & 0,096 & 5,171 & $5,223^{* *}$ & Não estacionária \\
\hline$\varphi$ & $0,489^{* *}$ & $0,123^{* * *}$ & $1,945^{* *}$ & $5,994^{* * *}$ & Não estacionária \\
\hline RN & 0,072 & 0,065 & $0,400^{*}$ & $1,445^{*}$ & Estacionária \\
\hline CAMB & $0,605^{* *}$ & $0,229 *$ & 5,644 & 16,689 & Não estacionária \\
\hline LTF & $1,387^{*}$ & $0,090^{* *}$ & 18,238 & 20,641 & Não estacionária \\
\hline Selic & $1,067^{*}$ & $0,181^{* *}$ & $2,622^{* *}$ & $3,020^{*}$ & Estacionária \\
\hline
\end{tabular}

Fonte: Elaboração própria a partir de resultados da pesquisa.

Notas: $\mathrm{N}=$ Ausência de constante e tendência; * significância a 1\%; ** significância a 5\%; *** significância a 10\%; $\left[H_{0}=\right.$ raiz unitária, $H_{1}=$ Estacionária $] \rightarrow$ (inverso do teste KPSS).

Quadro 3 - Testes de raiz unitária para as variáveis do modelo em nível: período de janeiro de 2011 a dezembro de 2014 (NME)

\begin{tabular}{|l|c|c|c|c|c|}
\hline Variável & \multicolumn{2}{|c|}{ Teste KPSS } & \multicolumn{2}{c|}{ Teste NG Perron } & Conclusão \\
\hline & Constante & $\begin{array}{c}\text { Constante e } \\
\text { tendência }\end{array}$ & Constante & $\begin{array}{c}\text { Constante e } \\
\text { tendência }\end{array}$ & \\
\hline $\bar{Y}$ & 0,287 & $0,125^{* * *}$ & $1,445^{*}$ & $4,468^{* *}$ & Estacionária \\
\hline $\bar{\pi}$ & $0,909^{* *}$ & $0,127^{*}$ & 7,500 & 8,824 & Não estacionária \\
\hline$\varphi$ & 0,118 & 0,118 & $0,194^{*}$ & $0,841^{*}$ & Estacionária \\
\hline RN & $0,453^{* *}$ & $0,131^{* * *}$ & $1,667^{*}$ & $4,145^{* *}$ & Estacionária \\
\hline CAMB & $1,026^{*}$ & 0,0477 & 22,150 & 7,229 & Não estacionária \\
\hline LTF & $0,91656^{*}$ & $0,14022^{*}$ & 41,8656 & 13,9380 & Não estacionária \\
\hline Selic & 0,267 & $0,241^{*}$ & $0,476^{*}$ & $0,827^{*}$ & Estacionária \\
\hline
\end{tabular}

Fonte: Elaboração própria a partir de resultados da pesquisa.

Notas: $\mathrm{N}=$ Ausência de constante e tendência; * significância a 1\%; ** significância a 5\%; ** * significância a $10 \% ;\left[H_{0}=\right.$ raiz unitária, $H_{1}=$ Estacionária $] \rightarrow$ (inverso do teste KPSS).

Em síntese, há nos modelos analisados um conjunto de variáveis estacionárias e não estacionárias ${ }^{13}$ em nível. Especificamente, no primeiro período constatou-se que as seguintes variáveis se comportaram com estacionariedade em nível: hiato

12 Quando ocorreu ambiguidade nos resultados dos testes KPSS e NG-Perron, o critério de decisão consistiu na verificação da estacionariedade através do teste de Dickey-Fuller a 5\% de significância.

13 O Apêndice A apresenta o detalhamento do comportamento temporal das variáveis analisadas no estudo. 
do produto, resultado nominal e taxa Selic. Já no segundo período, hiato do produto, desvio da inflação, resultado nominal e a própria Selic apresentaram tal comportamento.

\subsection{Identificação das Defasagens do Modelo}

Para determinação do número de defasagens das variáveis endógenas do modelo, utilizou-se o critério de informação de Schwarz (BIC). De acordo com o BIC, as defasagens ótimas para as variáveis do modelo são duas no modelo do TM e uma defasagem no modelo da NME. Como aponta Bueno (2011), o critério BIC estima assintoticamente a ordem de defasagem sob condições gerais, além de ser o critério mais parcimonioso na escolha da defasagem ótima. Assim, realizados os testes, definiu-se como sendo duas defasagens (dois meses - TM) e uma defasagem (um mês - NME) a ordem de defasagem nos dois modelos estimados (ver Quadro 4).

Quadro 4 - Critério de informação de Schwarz: ordem de seleção do VAR no TM e NME

\begin{tabular}{|l|c|c|}
\hline Lags & VAR no TM & VAR no NME \\
\hline 1 & $-0,41$ & $-6,78^{*}$ \\
\hline 2 & $-0,93^{*}$ & $-5,71$ \\
\hline 3 & $-0,11$ & $-4,56$ \\
\hline 4 & 1,25 & $-3,59$ \\
\hline
\end{tabular}

Fonte: Elaboração própria a partir de resultados da pesquisa.

\subsection{Relação de Equilibrio de Longo Prazo entre as Variáveis do Modelo}

Para se testar a hipótese de que há uma relação de equilíbrio de longo prazo entre as variáveis do modelo, foi realizado o teste de cointegração de Johansen. Conforme exposto por Sims, Stock e Watson (1990), a identificação de cointegração entre as variáveis se faz necessária para possibilitar a análise do VAR em nível e, assim, certificar-se sobre a solidez na análise realizada - para certificar-se da existência de equilíbrio entre as variáveis que compõem os modelos estudados.

Para a realização do teste no TM, foi considerado todo o período de análise. No teste de cointegração de Johansen, foi considerada a existência de intercepto no vetor de cointegração e ausência de tendência linear no vetor de cointegração e no nível. Ainda, utilizou-se o intervalo de duas defasagens no teste de cointegração. O resultado do teste de cointegração é apresentado no Quadro 5. Verifica-se, pelo teste traço, que ao nível de 5\% de significância há três vetores de cointegração. 
Quadro 5 - Teste de cointegração para as variáveis do modelo: TM e NME

\begin{tabular}{|l|c|c|c|}
\hline $\boldsymbol{r}_{\mathbf{0}} \mathbf{T M}$ & $\lambda_{\text {traco }}(\boldsymbol{r}) \mathbf{T M}$ & $\boldsymbol{r}_{\mathbf{0}} \mathbf{N M E}$ & $\lambda_{\text {traco }}(\boldsymbol{r}) \mathbf{N M E}$ \\
\hline Lags $=2$ & & Lags $=1$ & \\
\hline $0^{*}$ & 0,445 & $0^{*}$ & 0,636 \\
\hline $1^{*}$ & 0,351 & $1^{*}$ & 0,555 \\
\hline $2^{*}$ & 0,218 & 2 & 0,438 \\
\hline 3 & 0,143 & 3 & 0,326 \\
\hline 4 & 0,131 & 4 & 0,243 \\
\hline 5 & 0,097 & 5 & 0,124 \\
\hline
\end{tabular}

Fonte: Elaboração própria a partir de resultados da pesquisa.

Nota: * rejeita-se $\left[H_{\mathrm{o}}=r \rightarrow\right.$ relações de cointegração existentes] o nível de $5 \%$ de significância.

Para a realização do teste na NME, foi considerado todo o período de análise. Também, foi considerada a existência de intercepto no vetor de cointegração e ausência de tendência linear no vetor de cointegração e no nível. Utilizou-se uma defasagem no teste de cointegração. O resultado do teste de cointegração consta no Quadro 5. Verifica-se que, ao nível de 5\% de significância, há dois vetores de cointegração.

Em síntese, os resultados para os dois testes evidenciam que existe equilíbrio de longo prazo entre as variáveis econômicas objeto do estudo. As evidências empíricas dão plausibilidade ao modelo teórico do estudo, bem como às análises apresentadas a seguir.

\subsection{Resposta da Política Monetária a Choques nas Variáveis do Modelo}

Um mecanismo utilizado para se analisar os resultados do modelo é a função resposta ao impulso, visto que mostra como um choque em uma variável endógena do modelo afeta as outras variáveis endógenas - bem como o efeito sobre si mesma. ${ }^{14}$

O período de análise compreende 12 períodos acumulados, o que equivale neste estudo a um ano. No TM, as respostas acumuladas da Selic a choques seguiram a seguinte ordenação de importância: SELIC, RN, CAMB, EXPINF, LFT, DESVIOINF e HIATO respectivamente.

14 Especificamente, os resultados demonstram como um choque de um desvio padrão na variável explicativa provoca uma resposta acumulada por parte da taxa Selic. 
Quadro 6 - Respostas acumuladas da Selic a choques nas variáveis do modelo: TM

\begin{tabular}{|c|c|c|c|c|c|c|c|}
\hline Períodos & $\begin{array}{c}\text { Resultado } \\
\text { nominal } \\
\text { (RN) }\end{array}$ & $\begin{array}{c}\text { Desvio da } \\
\text { inflação } \\
\text { acumulada } \\
(\varphi)\end{array}$ & $\begin{array}{c}\text { Letras fi- } \\
\text { nanceiras } \\
\text { do Tesouro } \\
\text { (LFT) }\end{array}$ & $\begin{array}{l}\text { Taxa de } \\
\text { câmbio } \\
\text { (CAMB) }\end{array}$ & $\begin{array}{c}\text { Expecta- } \\
\text { tiva da } \\
\text { inflação } \\
(\bar{\pi})\end{array}$ & $\begin{array}{c}\text { Hiato do } \\
\text { produto } \\
(\bar{Y})\end{array}$ & $\begin{array}{c}\text { Taxa de } \\
\text { juros } \\
\text { interna } \\
\text { (SELIC) }\end{array}$ \\
\hline 1 & $-0,030$ & $-0,064$ & 0,043 & $-0,006$ & 0,025 & $-0,019$ & 0,270 \\
\hline 2 & $-0,136$ & $-0,109$ & 0,103 & 0,049 & 0,125 & $-0,093$ & 0,722 \\
\hline 3 & $-0,352$ & $-0,105$ & 0,186 & 0,156 & 0,323 & $-0,163$ & 1,292 \\
\hline 4 & $-0,646$ & $-0,047$ & 0,281 & 0,340 & 0,617 & $-0,201$ & 1,934 \\
\hline 5 & $-1,007$ & 0,051 & 0,396 & 0,592 & 0,978 & $-0,208$ & 2,606 \\
\hline 6 & $-1,420$ & 0,178 & 0,538 & 0,904 & 1,372 & $-0,183$ & 3,273 \\
\hline 7 & $-1,856$ & 0,321 & 0,709 & 1,261 & 1,764 & $-0,131$ & 3,903 \\
\hline 8 & $-2,291$ & 0,471 & 0,915 & 1,643 & 2,127 & $-0,059$ & 4,472 \\
\hline 9 & $-2,702$ & 0,620 & 1,157 & 2,033 & 2,439 & 0,025 & 4,963 \\
\hline 10 & $-3,072$ & 0,765 & 1,437 & 2,414 & 2,690 & 0,117 & 5,364 \\
\hline 11 & $-3,389$ & 0,904 & 1,752 & 2,772 & 2,877 & 0,209 & 5,671 \\
\hline 12 & $-3,645$ & 1,037 & 2,099 & 3,098 & 3,007 & 0,296 & 5,886 \\
\hline
\end{tabular}

Fonte: Elaboração própria a partir de resultados da pesquisa.

Verifica-se, portanto, que no TM, cujos resultados são apresentados no Quadro 6, prevaleceu um elevado componente de inercialidade na taxa de juros. Ademais, a política monetária respondeu positivamente a choques nas variáveis do modelo, com exceção do resultado nominal - ou seja, a política monetária respondeu com reduções na Selic a choques positivos nessa variável, ao mesmo tempo que respondeu elevando a Selic frente a choques positivos na taxa de câmbio, expectativa de inflação, LFT, desvio da inflação e, mais fracamente, ao hiato do produto.

Nesse sistema, a política monetária respondeu com mais intensidade a choques acumulados na própria Selic no resultado nominal, na taxa de câmbio e na expectativa da inflação, dando menor força ao desvio da inflação e ao hiato do produto.

Por sua vez, na NME, cujos resultados são apresentados no Quadro 7, também se verifica que prevaleceu um elevado componente de reflexividade na taxa de juros. Ademais, e distintamente do período do TM, a política monetária respondeu positivamente a choques nas seguintes variáveis Selic, desvio da inflação, LFT, $\mathrm{RN}$ e hiato - ou seja, a política monetária respondeu com elevações na Selic a choques positivos nestas, ao mesmo tempo que respondeu reduzindo a Selic frente a choques positivos na taxa de câmbio e a expectativa de inflação. 
Quadro 7 - Respostas acumuladas da Selic a choques nas variáveis do modelo: NME

\begin{tabular}{|c|c|c|c|c|c|c|c|}
\hline Períodos & $\begin{array}{c}\text { Resultado } \\
\text { nominal } \\
\text { (RN) }\end{array}$ & $\begin{array}{c}\text { Desvio da } \\
\text { inflação } \\
\text { acumulada } \\
(\varphi)\end{array}$ & $\begin{array}{c}\text { Letras fi- } \\
\text { nanceiras } \\
\text { do Tesouro } \\
\text { (LTF) }\end{array}$ & $\begin{array}{l}\text { Taxa de } \\
\text { câmbio } \\
\text { (CAMB) }\end{array}$ & $\begin{array}{c}\text { Expecta- } \\
\text { tiva da } \\
\text { inflação } \\
(\bar{\pi})\end{array}$ & $\begin{array}{l}\text { Hiato do } \\
\text { produto } \\
(\bar{Y})\end{array}$ & $\begin{array}{l}\text { Taxa de } \\
\text { juros } \\
\text { interna } \\
\text { (SELIC) }\end{array}$ \\
\hline 1 & $-0,006$ & 0,069 & 0,030 & $-0,050$ & 0,001 & 0,046 & 0,143 \\
\hline 2 & 0,012 & 0,176 & 0,098 & $-0,086$ & $-0,021$ & 0,079 & 0,401 \\
\hline 3 & $-0,016$ & 0,322 & 0,198 & $-0,121$ & $-0,076$ & 0,130 & 0,748 \\
\hline 4 & 0,066 & 0,508 & 0,325 & $-0,154$ & $-0,134$ & 0,204 & 1,159 \\
\hline 5 & 0,139 & 0,729 & 0,455 & $-0,194$ & $-0,185$ & 0,287 & 1,617 \\
\hline 6 & 0,235 & 0,979 & 0,589 & $-0,246$ & $-0,231$ & 0,367 & 2,103 \\
\hline 7 & 0,345 & 1,251 & 0,720 & $-0,307$ & $-0,279$ & 0,437 & 2,602 \\
\hline 8 & 0,465 & 1,543 & 0,841 & $-0,374$ & $-0,332$ & 0,499 & 3,101 \\
\hline 9 & 0,590 & 1,850 & 0,948 & $-0,447$ & $-0,385$ & 0,549 & 3,593 \\
\hline 10 & 0,719 & 2,165 & 1,038 & $-0,526$ & $-0,435$ & 0,588 & 4,072 \\
\hline 11 & 0,849 & 2,479 & 1,110 & $-0,608$ & $-0,480$ & 0,613 & 4,532 \\
\hline 12 & 0,982 & 2,786 & 1,160 & $-0,690$ & $-0,523$ & 0,626 & 4,969 \\
\hline
\end{tabular}

Fonte: Elaboração própria a partir de resultados da pesquisa.

Frisa-se que tanto no TM quanto na NME, considerando-se as respostas acumuladas da Selic em face de choques na própria, verificou-se um elevado componente de reflexividade da taxa de juros. Esse resultado evidencia que os choques da Selic foram expressivos para o comportamento posterior da própria Selic, independente do período analisado. Contudo, quando esse resultado é confrontado com o comportamento verificado na própria Selic para o período discutido, tem-se evidência de gradualismo na condução da política monetária no TM, dada a forma como a gestão da política monetária foi conduzida no período, considerando-se a ausência de surpresas nas expectativas quanto ao comportamento da Selic e a busca pela ancoragem das expectativas, bem como as conservadoras mudanças ocorridas na taxa de juros, as quais suavizavam o comportamento dos juros. Contudo, quando analisada a NME, o mesmo resultado do elevado componente de reflexividade traz evidência de rompimento com o gradualismo, em face da gestão da política monetária ocorrida no período, considerando-se que surpresas nas expectativas dos agentes passaram a coexistir com a política monetária, a ancoragem das expectativas foi abalada nesse período e houve significativas e contínuas reduções dos juros verificada no período, mesmo quando inesperadas pelos agentes.

Em síntese, verificam-se significativas distinções no comportamento da política monetária face a choques nas variáveis do modelo. Enquanto, no TM, a política 
monetária reagiu a choques nas variáveis, conforme previsto em um $\mathrm{RMI}^{15}$ (ver Gráfico 1), o mesmo não ocorreu em plenitude na NME. Trata-se, portanto, de uma evidência acerca do notável afrouxamento do RMI por parte da política monetária na vigência da $\mathrm{NME}^{16}$ (ver Gráfico 2).

Gráfico 1 - Função resposta ao impulso acumulada (Selic): TM
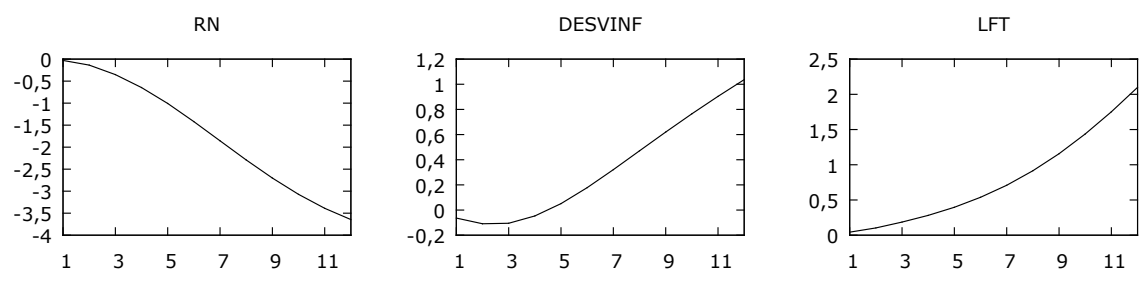

CAMB
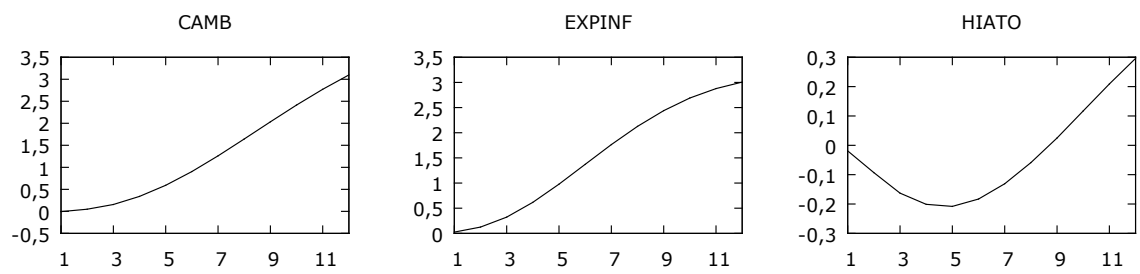

SELIC

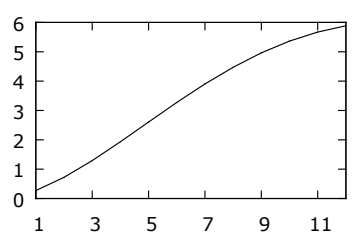

Fonte: Elaboração própria a partir de resultados da pesquisa.

15 Notadamente, em face às respostas positivas a choques positivos no desvio da inflação e das expectativas da inflação - componente forward looking, que, nesse caso, foi mais forte do que o primeiro.

16 As respostas na NME foram coerentes com o RMI acerca do desvio da inflação, mas o resultado acerca das expectativas da inflação não foi. Além disso, na NME, chamou atenção o resultado da taxa de câmbio, o qual demonstrou que choques com desvalorização cambial foram respondidos com reduções da Selic. 
Gráfico 2 - Função resposta ao impulso acumulada (Selic): NME
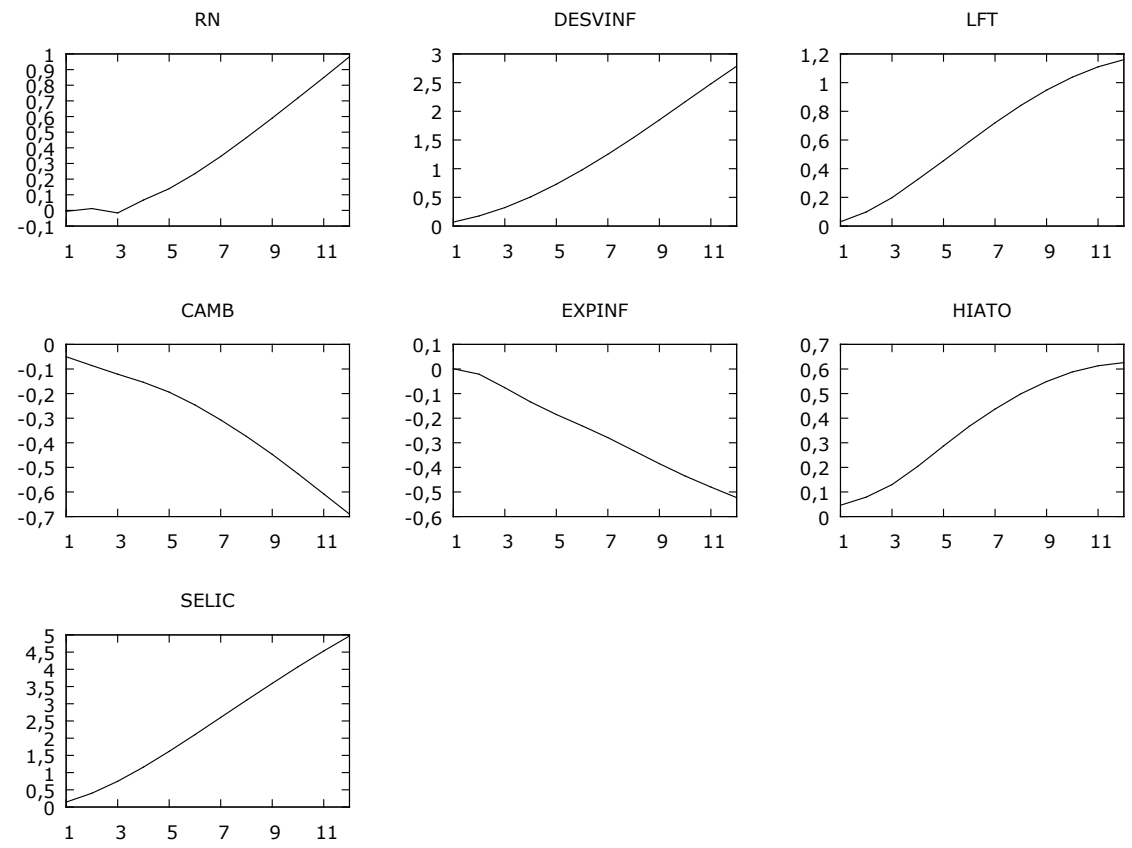

Fonte: Elaboração própria a partir de resultados da pesquisa.

Ressalta-se que, na NME, conforme resultados obtidos, prevaleceram fortes respostas acumuladas da Selic frente a choques nela mesma e, em menor magnitude, ao desvio da inflação, porém com baixos impactos das demais variáveis do modelo.

Em síntese, discutindo-se os resultados obtidos neste estudo com as conclusões obtidas nos demais trabalhos apresentados na revisão da literatura, conclui-se que, no TM, uma característica se mostrou peculiar. Especificamente, há convergência nos resultados (endossada por este trabalho) da predominância de elevado gradualismo na condução da política monetária (tendo em vista o forte componente inercial e o conservadorismo nas variações da taxa de juros) combinada com um forte componente forward looking na gestão monetária. Desse modo, a política monetária foi conduzida com precaução, no sentido de não trazer mudanças bruscas nos juros, buscando ancorar as expectativas dos agentes.

Por sua vez, percebem-se fortes evidências de mudanças introduzidas no período da NME, no qual o gradualismo foi rompido (pois a política monetária reagiu fortemente a choques na própria Selic em face das significativas e contínuas reduções do período), ao mesmo tempo que o componente forward looking, então predominante, entrou em declínio. Esse resultado aponta que o objetivo de ancorar 
as expectativas dos agentes (como se espera no RMI) perdeu relevância na NME. Neste sistema, surpresas às expectativas dos agentes passaram a coexistir com a política monetária. Sintetizando, as duas evidências obtidas na NME, o rompimento com o gradualismo e o declínio da relevância do componente forward looking, sinalizam uma mudança na política monetária em relação ao TM e um importante elemento teórico existente no RMI, o qual consiste na ancoragem das expectativas.

\subsection{Efeitos de Choques Inesperados nos Mecanismos Endógenos sobre a Taxa de Juros}

Outra forma de explorar as relações entre as variáveis endógenas do modelo macroeconômico estimado é através da decomposição da variância do erro de previsão. Esta mostra qual a porcentagem da variância do erro de previsão que decorre de cada variável endógena ao longo do horizonte de previsão. ${ }^{17}$ Os resultados obtidos são apresentados nos Quadros 8 e 9.

Quadro 8 - Decomposição da variância do erro de previsão: TM

\begin{tabular}{|l|c|c|c|c|c|c|c|}
\hline Período & $\begin{array}{c}\text { Resultado } \\
\text { nominal }\end{array}$ & $\begin{array}{c}\text { Desvio da } \\
\text { inflação } \\
\text { acumulada }\end{array}$ & $\begin{array}{c}\text { Letras fi- } \\
\text { nanceiras } \\
\text { do Tesouro }\end{array}$ & $\begin{array}{c}\text { Taxa de } \\
\text { câmbio }\end{array}$ & $\begin{array}{c}\text { Expecta- } \\
\text { tiva da } \\
\text { inflação }\end{array}$ & $\begin{array}{c}\text { Hiato do } \\
\text { produto }\end{array}$ & $\begin{array}{c}\text { Taxa de } \\
\text { juros } \\
\text { interna }\end{array}$ \\
\hline 1 & 1,145 & 5,135 & 2,322 & 0,047 & $\mathbf{0 , 7 8 9}$ & $\mathbf{0 , 4 5 8}$ & $\mathbf{9 0 , 1 0 2}$ \\
\hline 2 & 3,780 & 1,931 & 1,719 & 0,596 & 3,358 & 1,833 & 86,780 \\
\hline 3 & 7,805 & 0,819 & 1,633 & 1,785 & 6,632 & 1,427 & 79,895 \\
\hline 4 & 10,475 & 0,686 & 1,540 & 3,412 & 9,817 & 0,878 & 73,187 \\
\hline 5 & 12,624 & 0,884 & 1,589 & 5,064 & 12,187 & 0,559 & 67,090 \\
\hline $\mathbf{6}$ & $\mathbf{1 4 , 4 3 1}$ & $\mathbf{1 , 1 4 8}$ & $\mathbf{1 , 7 7 3}$ & $\mathbf{6 , 7 3 3}$ & $\mathbf{1 3 , 6 4 5}$ & $\mathbf{0 , 4 1 5}$ & $\mathbf{6 1 , 8 5 2}$ \\
\hline 7 & 15,863 & 1,396 & 2,098 & 8,356 & 14,353 & 0,387 & 57,544 \\
\hline 8 & 16,947 & 1,610 & 2,596 & 9,881 & 14,512 & 0,425 & 54,026 \\
\hline 9 & 17,705 & 1,793 & 3,296 & 11,273 & 14,314 & 0,498 & 51,118 \\
\hline 10 & 18,160 & 1,954 & 4,223 & 12,491 & 13,916 & 0,584 & 48,668 \\
\hline 11 & 18,339 & 2,100 & 5,394 & 13,500 & 13,435 & 0,6689 & 46,559 \\
\hline $\mathbf{1 2}$ & $\mathbf{1 8 , 2 7 9}$ & $\mathbf{2 , 2 3 6}$ & $\mathbf{6 , 8 0 5}$ & $\mathbf{1 4 , 2 7 5}$ & $\mathbf{1 2 , 9 5 0}$ & $\mathbf{0 , 7 3 8}$ & $\mathbf{4 4 , 7 1 4}$ \\
\hline
\end{tabular}

Fonte: Elaboração própria a partir de resultados da pesquisa.

17 Mais especificamente, mede a importância do erro da j-ésima equação na explicação dos movimentos inesperados da taxa Selic. 
Quadro 9-Decomposição da variância do erro de previsão: NME

\begin{tabular}{|l|l|l|l|l|l|l|l|}
\hline Periodo & $\begin{array}{l}\text { Resultado } \\
\text { nominal }\end{array}$ & $\begin{array}{l}\text { Desvio da } \\
\text { inflação } \\
\text { acumulada }\end{array}$ & $\begin{array}{l}\text { Letras fi- } \\
\text { nanceiras } \\
\text { do Tesouro }\end{array}$ & $\begin{array}{l}\text { Taxa de } \\
\text { câmbio }\end{array}$ & $\begin{array}{l}\text { Expecta- } \\
\text { tiva da } \\
\text { inflação }\end{array}$ & $\begin{array}{l}\text { Hiato do } \\
\text { produto }\end{array}$ & $\begin{array}{l}\text { Taxa de } \\
\text { juros } \\
\text { interna }\end{array}$ \\
\hline 1 & $\mathbf{0 , 1 1 8}$ & $\mathbf{1 5 , 3 6 8}$ & $\mathbf{3 , 0 7 4}$ & $\mathbf{8 , 1 5 8}$ & $\mathbf{0 , 0 0 5}$ & $\mathbf{6 , 9 2 7}$ & $\mathbf{6 6 , 3 4 7}$ \\
\hline 2 & 0,064 & 14,016 & 4,778 & 3,312 & 0,458 & 2,808 & 74,561 \\
\hline 3 & 0,325 & 13,648 & 5,592 & 1,842 & 1,264 & 2,108 & 75,217 \\
\hline 4 & 0,668 & 14,193 & 6,223 & 1,216 & 1,347 & 2,221 & 74,128 \\
\hline 5 & 1,084 & 15,130 & 6,075 & 0,971 & 1,189 & 2,266 & 73,281 \\
\hline $\mathbf{6}$ & $\mathbf{1 , 5 7 8}$ & $\mathbf{1 6 , 1 1 9}$ & $\mathbf{5 , 8 5 6}$ & $\mathbf{0 , 9 2 3}$ & $\mathbf{1 , 0 1 8}$ & $\mathbf{2 , 1 5 9}$ & $\mathbf{7 2 , 3 4 4}$ \\
\hline 7 & 2,008 & 17,161 & 5,576 & 0,943 & 0,928 & 1,969 & 71,411 \\
\hline 8 & 2,373 & 18,278 & 5,241 & 0,992 & 0,892 & 1,776 & 70,445 \\
\hline 9 & 2,673 & 19,423 & 4,881 & 1,066 & 0,868 & 1,595 & 69,491 \\
\hline 10 & 2,932 & 20,519 & 4,514 & 1,157 & 0,841 & 1,429 & 68,603 \\
\hline 11 & 3,172 & 21,493 & 4,163 & 1,252 & 0,815 & 1,285 & 67,816 \\
\hline $\mathbf{1 2}$ & $\mathbf{3 , 4 0 6}$ & $\mathbf{2 2 , 3 0 7}$ & $\mathbf{3 , 8 4 2}$ & $\mathbf{1 , 3 3 7}$ & $\mathbf{0 , 7 9 1}$ & $\mathbf{1 , 1 6 7}$ & $\mathbf{6 7 , 1 4 6}$ \\
\hline
\end{tabular}

Fonte: Elaboração própria a partir de resultados da pesquisa.

Em síntese, através da decomposição da variância do erro de previsão, a ordenação de relevância obtida pelas variáveis, tanto no TM quanto na NME, foi condizente com os resultados obtidos através das respostas aos impulsos.

Explorando o Quadro 8, referente ao TM, para o final de 12 períodos, a variável Selic possui aproximadamente $44 \%$ de sua variância explicada por ela mesma, sendo que cerca de $18 \%$ de sua variância é atribuída a choques na variável resultado nominal. Essas duas variáveis representam aproximadamente $60 \%$ da contribuição ao caso. Além disso, destacam-se as variáveis taxa de câmbio e expectativa de inflação, explicando, respectivamente, 14,27\% e 12,95\% da variância do erro de previsão.

Para o Quadro 9, referente à NME, no final dos mesmos 12 períodos, tem-se a Selic com 67\% de sua variância explicada por ela mesma, sendo que, em torno de 22\%, é atribuído aos choques na variável desvio da inflação acumulada. São as duas variáveis essenciais, com aproximadamente $90 \%$ de contribuição ao caso. Além disso, em absoluta menor relevância, cabe destacar as variáveis letras financeiras do tesouro e resultado nominal, explicando, respectivamente, 3,84\% e 3,40\% da variância do erro de previsão.

A significativa porcentagem da variância do erro de previsão da taxa interna de juros explicada por ela mesma destaca o alto grau de reflexividade da variável em ambos os períodos, TM e NME. Os resultados encontrados pela decomposição da variância dos erros de previsão no TM corroboram os resultados encontrados pela função impulso-resposta, em que as variáveis Selic, resultado nominal e taxa 
de câmbio foram as mais importantes para demonstrar o comportamento da taxa interna de juros. Já para o NME, tem-se o mesmo reforço, alterando as variáveis para Selic, desvio da inflação acumulada e letras financeiras do Tesouro. Observa-se, ainda, que, no período do TM, os movimentos inesperados da taxa Selic derivaram do componente gradual da Selic, resultado nominal, taxa de câmbio e expectativa de inflação, enquanto que, na NME, os movimentos inesperados da taxa Selic derivaram da própria tendência assumida pela Selic e pelos desvios observados no desvio da meta.

\section{Considerações Finais}

Este artigo objetivou identificar através de VARs as respostas da política monetária a choques em um modelo de regra de Taylor modificado, contemplando o período do TM (2000-2011) e da NME (2012-2014). Para tanto, utilizou-se VAR em nível, analisando-se preliminarmente a existência de relação de equilíbrio de longo prazo entre as variáveis.

Tal metodologia permitiu identificar se existiram diferenças significativas na gestão da política monetária. Os resultados obtidos evidenciam diferenças significativas na gestão da política monetária entre os dois sistemas.

Especificamente, verificou-se que, no TM, a política monetária reagiu fortemente a choques na própria Selic, resultado nominal, taxa de câmbio e expectativa da inflação, dando menores respostas ao desvio da inflação e hiato do produto. Prevaleceu, portanto, elevada atenção à Selic (evidência de gradualismo para o período, como discutido nos resultados), ao lado fiscal, ao pass-through cambial e a um componente forward-looking na gestão monetária nesse período. De fato, pouco se considerou o lado real da economia - como evidenciado pelo hiato do produto.

Por sua vez, na NME, a política monetária reagiu fortemente a choques na própria Selic (evidência do rompimento com o gradualismo, como discutido nos resultados, e no desvio da inflação, dando marginalizada importância às demais variáveis. Trata-se de uma diferença notória e importante, a qual aponta, inclusive, o afrouxamento do RMI no período da NME.

Ademais, a forma da reação frente aos choques na vigência da NME foi distinta em relação ao período do TM. Enquanto neste a política monetária reagiu positivamente a choques em todas as variáveis do modelo, com exceção do resultado nominal, a NME reagiu positivamente a choques em todas as variáveis - com exceção da taxa de câmbio e da expectativa de inflação. Outra diferença significativa. Nesse caso, há, portanto, evidência de baixa atenção para ambas as variáveis, seja em magnitude, seja em termos de sinais obtidos - que são opostos ao previstos teoricamente em um regime em que prevalecem metas de inflação. 
Com isso, verifica-se que, no TM, a gestão da política monetária prestou maior atenção ao conjunto de variáveis analisadas, enquanto, na vigência da NME, a política monetária focou, basicamente, em apenas duas - a própria Selic e o desvio da inflação. Conforme exposto na análise das funções impulso-resposta e da decomposição da variância do erro de previsão, essas duas variáveis foram bastante representativas na gestão da política monetária. Por conseguinte, sintetizando as duas evidências obtidas na NME, o rompimento com o gradualismo e o declínio da relevância do componente forward looking, verifica-se uma mudança na política monetária em relação ao TM e um importante elemento teórico existente neste, o qual consiste na ancoragem das expectativas dos agentes econômicos.

Com efeito, acerca da questão que norteou a pesquisa, esta pode ser respondida de forma afirmativa, ou seja, a condução da política monetária foi alterada nos períodos entre 2000 e 2011 (TM) e 2012 e 2014 (NME)? Sim, as evidências apontam afirmativamente, conforme elementos aqui expostos, dando-se especial atenção ao afrouxamento do RMI durante o período da NME.

\section{Referências}

BALBINO, C. E.; COLLA, E.; TELES, V. K. A política monetária brasileira sob o RMI. Revista Brasileira de Economia, v. 65, n. 2, 2011.

BARBOSA, F. H.; CAMÊLO, F. D.; JOAO, I. C. A taxa de juros natural e a regra de Taylor no Brasil: 2003-2015. Revista Brasileira de Economia, v. 70, n. 4, p. 18, 2016.

BARBOSA FILHO, F. H. A crise econômica de 2014/2017. Estudos Avançados, v. 31, n. 89, 2017.

BERNANKE, B. S.; MISHKIN, F. S. Inflation targeting: a new framework for monetary policy? NBER Working Paper, n. 5893, p. 11, 1997.

BIONDI, R. L; TONETO JR., R. Regime de metas inflacionárias: os impactos sobre o desempenho econômico dos países. Estudos Econômicos, São Paulo, v. 38, n. 4, p. 873-903, dez. 2008.

BRAGA, B. P. M.; PEREIRA, J. I. R. Sistema de metas de inflação no Brasil: uma análise da estrutura. Revista Economia e Tecnologia, v. 10, n. 1, 2014.

BUENO, R. L. S. The Taylor rule under inquiry: hidden states. FGV Working Paper, 2005. Disponível em: http://bibliotecadigital.fgv.br/dspace/handle/10438/12446?show=full. Acesso em: 28 ago. 2016.

BUENO, R. L. S. Econometria de séries temporais. 2. ed. São Paulo: Cengage Learning, 2011.

CAMPOS, B. G. Credibilidade e função de reação do Banco Central do Brasil. 2015. Dissertação (Mestrado) - Fundação Getúlio Vargas, Rio de Janeiro, 2015. 
CARRARA, A. F.; CORREA, A. L. O RMI no Brasil: uma análise empírica do IPCA. Revista de Economia Contemporânea, v. 16, n. 3, 2012.

CHOI, W. G.; WEN, Y. Dissecting Taylor rules in a structural VAR. Federal Reserve Bank of St. Louis Working Paper Series, n. 005A, 2010. Disponível em: http://research.stlouisfed.org/ wp/2010/2010-005.pdf. Acesso em: 28. ago. 2016.

CLARIDA, R.; GALI, J.; GERTLER, M. Monetary policy rules in practice: some international evidence. European Economic Review, v. 42, 1998.

CORREIA, F.; AMARAL, R. Política monetária e a determinação da função reação do Banco Central Brasileiro. Revista Economia \& Desenvolvimento, v. 7, n. 1, 2008.

COSTA FILHO, A. E. A política monetária do Banco Central durante a presidência de Henrique Meirelles. Análise Econômica, n. 60, 2013.

GALÍ, J.; LÓPEZ-SALIDO, J. D.; VALLÉS, J. Understanding the effects of government spending on consumption. Journal of the European Economic Association, v. 5, n. 1, 2007.

HAMILTON, J. D. Time series analysis. Princeton: Princeton Press, 1994.

KYDLAND, F. E.; PRESCOTT, E. Time to build and aggregate fluctuations. Econometrica, V. 50, n. $6,1982$.

MANTEGA, G. O primeiro ano da nova matriz econômica. Valor econômico, 19 dez. 2012. Disponível em: http://www.valor.com.br/brasil/2945092/o-primeiro-ano-da-nova-matriz-economica. Acesso em: 1. maio 2018.

MENDONÇA, H. F. Independência do Banco Central e Coordenação de Políticas: vantagens e desvantagens de duas estruturas para estabilização. Revista de Economia Política, v. 23, n. 1, 2003.

MINELLA, A. Monetary policy and inflation in Brazil (1975-2000): a VAR estimation. Revista Brasileira de Economia, v. 57, n. 3, 2003.

MINELLA, A. et al. Inflation targeting in Brazil: lessons and challenges. Banco Central do Brasil Working Paper Series, n. 53, 2002.

MINELLA, A. et al. Inflation targeting in Brazil: constructing credibility under exchange rate volatility. Journal of International Money and Finance, v. 22, n. 7, 2003.

MISHKIN, F. S. Inflation targeting in emerging-market countries. American Economic Review, v. 90, n. $2,2000$.

MODENESI, A. M. Convenção e rigidez na política monetária: uma estimativa da função de reação do BCB - 2000-2007. Texto Para Discussão - IPEA, n. 1351, p. 10, 2008. Disponível em: http://www.ipea.gov.br/portal/images/stories/PDFs/TDs/td_1351.pdf. Acesso em: 28. ago. 2016.

MODENESI, A. M.; MODENESI, R. L. Quinze anos de rigidez monetária no Brasil pós-Plano Real: uma agenda de pesquisa. Revista de Economia Política, v. 32, n. 3, 2012. 
OREIRO, J. L. Muito além do tripé: proposta de um novo regime de política macroeconômica para dobrar a renda per-capita em 20 anos. In: CARVALHO, L. et al. (org.). Indústria e desenvolvimento produtivo no Brasil. Rio de Janeiro: FGV: Elsevier, 2015. Disponível em: https:/www.researchgate.net/profile/Joseluis_Oreiro/publication/272829706_Muito_alem_do_ tripe_proposta_de_um_novo_regime_de_politica_macroeconomica_para_dobrar_a_renda_per-capita_em_20_anos/links/54fodcce0cf2f9e34efd1c98.pdf. Acesso em: 12 ago. 2018.

PALMA, A. A.; PORTUGAL, M. S. Preferences of the Central Bank of Brazil under the inflation targeting regime: commitment vs. discretion. Revista Brasileira de Economia, v. 65, n. 4, 2011.

POLICANO, R.; BUENO, R. A sensibilidade da política monetária no Brasil: 1999- 2005. In: ENCONTRO NACIONAL DE ECONOMIA, 34., 2006, Salvador. Anais eletrônicos [...]. Salvador: ANPEC, 2006.

SILVA, C. O. Análise da função de reação do Banco Central do Brasil entre 2000 e 2012: inclusão de preços de ativos, não linearidade e queda da taxa de juros neutra. 2012. Dissertação (Mestrado) - Fundação Getúlio Vargas, Rio de Janeiro, 2012.

SIMS, C.; STOCK, J.; WATSON, M. Inference in linear time series models with some unit roots. Econometrica, v. 58, p.113-144, 1990.

TAYLOR, J. B. Discretion versus policy rules in practice. Journal of Monetary Economics, v. 39, n. 1, p. 195-214, 1993.

VELOSO, F.; BONELLI, R. (org.). A crise do crescimento no Brasil. 1. ed. Rio de Janeiro: Elsevier: FGV/IBRE, 2016.

\section{Apêndice A - Comportamento das Variáveis do Modelo entre 2000 e 2014}
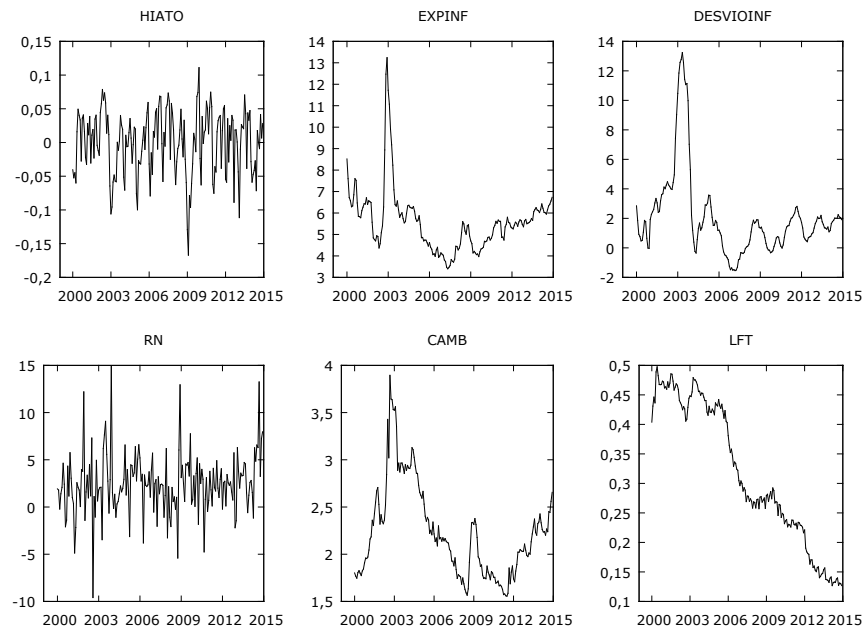

Fonte: Elaboração própria a partir de resultados da pesquisa. 


\section{Apêndice B - Verificação da Estabilidade dos Modelos Estimados: Raízes do Polinômio Característico}

\begin{tabular}{|l|l|}
\hline Raiz & Módulo \\
\hline 0,996779 & 0,996779 \\
\hline 0,907923 & 0,907923 \\
\hline 0,899278 & 0,899278 \\
\hline $0,854814-0,221988 i$ & 0,883168 \\
\hline $0,854814+0,221988 i$ & 0,883168 \\
\hline $0,764955-0,129363 i$ & 0,775817 \\
\hline $0,764955+0,129363 i$ & 0,775817 \\
\hline $0,394929-0,190869 i$ & 0,438634 \\
\hline $0,394929+0,190869 i$ & 0,438634 \\
\hline$-0,222938-0,337359 i$ & 0,404367 \\
\hline$-0,222938+0,337359 i$ & 0,404367 \\
\hline $0,291482-0,279248 i$ & 0,403660 \\
\hline $0,291482+0,279248 i$ & 0,403660 \\
\hline$-0,326964$ & 0,326964 \\
\hline
\end{tabular}

Fonte: Elaboração própria a partir de resultados da pesquisa.

Condição de estabilidade satisfeita: inverso das raízes dentro do círculo unitário.

Raízes do polinômio característico

\begin{tabular}{|l|l|}
\hline Raiz & Módulo \\
\hline 0,993615 & 0,993615 \\
\hline $0,900327-0,087723 i$ & 0,904590 \\
\hline $0,900327+0,087723 \mathrm{i}$ & 0,904590 \\
\hline $0,813661-0,305489 \mathrm{i}$ & 0,869119 \\
\hline $0,813661+0,305489 \mathrm{i}$ & 0,869119 \\
\hline $0,214772-0,658247 \mathrm{i}$ & 0,692399 \\
\hline $0,214772+0,658247 \mathrm{i}$ & 0,692399 \\
\hline $0,384024-0,488106 \mathrm{i}$ & 0,621065 \\
\hline $0,384024+0,488106 \mathrm{i}$ & 0,621065 \\
\hline$-0,407322-0,298882 \mathrm{i}$ & 0,505215 \\
\hline$-0,407322+0,298882 \mathrm{i}$ & 0,505215 \\
\hline$-0,339745$ & 0,339745 \\
\hline $0,018702-0,170743 \mathrm{i}$ & 0,171765 \\
\hline $0,018702+0,170743 \mathrm{i}$ & 0,171765 \\
\hline
\end{tabular}

Fonte: Elaboração própria a partir de resultados da pesquisa. 
Condição de estabilidade satisfeita: inverso das raízes dentro do círculo unitário.

\section{Apêndice C - Testes de Autocorrelação de Breusch-Godfrey nos Modelos Estimados:}

TM

\begin{tabular}{|l|l|l|}
\hline Lags & LM-Stat & Prob \\
\hline 1 & 58,77692 & 0,1599 \\
\hline 2 & 55,64598 & 0,2389 \\
\hline 3 & 41,29219 & 0,7750 \\
\hline 4 & 64,10173 & 0,0724 \\
\hline 5 & 63,23700 & 0,0831 \\
\hline 6 & 66,02803 & 0,0527 \\
\hline 7 & 62,41342 & 0,0944 \\
\hline 8 & 64,92456 & 0,0634 \\
\hline 9 & 44,63635 & 0,6505 \\
\hline 10 & 73,84425 & 0,0124 \\
\hline 11 & 42,94209 & 0,7160 \\
\hline 12 & 99,10655 & 0,0000 \\
\hline
\end{tabular}

Fonte: Elaboração própria a partir de resultados da pesquisa.

Conclusão: não se rejeita a hipótese nula de ausência de correlação serial nos erros.

NME

\begin{tabular}{|l|l|l|}
\hline Lags & LM-Stat & Prob \\
\hline 1 & 47,00924 & 0,5542 \\
\hline 2 & 76,62653 & 0,0070 \\
\hline 3 & 44,92322 & 0,6391 \\
\hline 4 & 61,44755 & 0,1093 \\
\hline 5 & 55,64161 & 0,2390 \\
\hline 6 & 50,69320 & 0,4066 \\
\hline 7 & 52,33642 & 0,3458 \\
\hline 8 & 41,48287 & 0,7685 \\
\hline 9 & 66,74259 & 0,0467 \\
\hline 10 & 33,78766 & 0,9519 \\
\hline 11 & 53,39499 & 0,3091 \\
\hline 12 & 48,06408 & 0,5110 \\
\hline
\end{tabular}

Fonte: Elaboração própria a partir de resultados da pesquisa.

Conclusão: não se rejeita a hipótese nula de ausência de correlação serial nos erros. 


\section{Autor correspondente:}

Thyago Américo Schio

E-mail: thyagoschio@gmail.com

Recebido em: 30/09/2017.

Aceito em: 28/11/2018.

(cc) BY 